\title{
Estratégias para pensar o digital
}

\author{
BEATRIZ ACCIOLY LINS \\ Universidade de São Paulo, São Paulo, Brasil \\ bia.accioly.lins@gmail.com \\ CAROLINA PARREIRAS \\ Universidade de São Paulo, São Paulo, Brasil \\ carolparreiras@gmail.com \\ ELIANE TÂNIA FREITAS \\ Universidade Federal do Rio Grande do Norte, Rio Grande do Norte, Brasil \\ etmart@gmail.com
}

DOI 10.11606/issn.2316-9133.v29i2pe181821

Este dossiê é organizado por três pesquisadoras do campo de estudos da antropologia digital, que vêm, desde pelo menos 2006, realizando pesquisas, participando de grupos de trabalho, mesas e seminários nos principais eventos nacionais ${ }^{1} \mathrm{e}$ internacionais ${ }^{2}$ da área de Antropologia, bem como publicando os resultados de suas pesquisas nessa área em livros e periódicos científicos (FREITAS; RAMOS 2017; FREITAS 2017; LINS 2019; 2020; PARREIRAS 2011; 2012; 2015; 2017; PARREIRAS; MACEDO 2020).

Nosso objetivo, ao propor à Cadernos de Campo este dossiê intitulado Estratégias para Pensar o Digital, é apresentar um quadro panorâmico de estudos contemporâneos sobre o digital, marcadamente por meio das experiências de pesquisadores/as jovens, alguns/mas dos/as quais procuraram na pesquisa mediada pela internet respostas para os desafios colocados pelas restrições de circulação e de contato advindas da pandemia da Covid-19. Em princípio, tal cenário parece instrumentalizar a internet como ferramenta de pesquisa, além de possibilitar um olhar fresco e atual sobre suas potencialidades e limitações em investigações nas Ciências Sociais.

Assim, o dossiê resulta de uma ampliação e de uma diversificação do interesse por esse campo de pesquisa, que, como a Antropologia como um todo, tende a trabalhar de modo incremental e a incorporar transformações negociadas a partir dos contextos concretos de

\footnotetext{
${ }^{1}$ Reunião Brasileira de Antropologia, ANPOCS, REA, Fazendo Gênero, ABCiber, dentre outros.

${ }^{2}$ Reunião de Antropologia do Mercosul, IUAES, Reunião Anual da American Anthropological Association, dentre outros.
} 
realização das pesquisas. Como bem nos lembram Clifford Geertz (2012) e a própria Christine Hine (2015 [2020]), em texto traduzido neste dossiê, é prática comum entre nós pesquisadoras/es pensar analiticamente sobre a necessidade de nos situarmos em campo. Assim, unimos duas pontas, em dois planos: um, mais abrangente, no qual damos continuidade a um trabalho coletivo, múltiplo, que se tem realizado em diversas frentes e instituições, e outro, mais particular ao contexto atual e que procura incorporar àquele primeiro plano novos/as pesquisadores/as e suas contribuições em pesquisas sobre, no e por meio do digital.

Desde seu surgimento e sua posterior popularização, a internet desperta o interesse de pesquisadores/as em diferentes campos disciplinares. Nas Ciências Sociais, e especificamente na Antropologia, tal interesse foi sendo formatado, desde a década de 1990, em um campo prolífico e robusto de estudos que tomam como foco a internet ou que dela se valem como ferramenta de pesquisa. Esses estudos primam pela diversidade temática e, ainda que tenham sido vistos com desconfiança por antropólogos/as mais tradicionais e conversadores/as, podemos dizer que temos hoje a legitimação de um subcampo chamado, seguindo a inspiração de Miller e Horst (2012), de "antropologia digital".

Se já há alguns anos se reconhece a importância desse campo de estudos, a pandemia da Covid-19 deixou claro o quanto as tecnologias, representadas por seus múltiplos dispositivos e pelas redes de conexão, são fundamentais para as relações que estabelecemos uns com os outros e com o mundo. A partir da digitalização de boa parte de nossas atividades - ou migração para formas remotas de interação, se preferirmos - fica patente a necessidade de complexificar nosso entendimento dos muitos usos e das muitas possibilidades oferecidas pela tecnologia e pelo digital.

O que chamamos aqui de digital se refere a um conjunto heterogêneo e bastante amplo de objetos, ações e relações sociotécnicas que se tornaram parte de nossa experiência cotidiana, modulada por marcadores sociais de classe, gênero, idade, raça, sexualidade, dentre outros. Já se tornou lugar comum entre estudiosos/as da Antropologia e das Ciências Sociais a afirmação de que não existe apenas uma internet para todos e todas, não existe apenas um Facebook ou um YouTube, pois, como pesquisadores/as, precisamos investigar como diferentes sujeitos ou grupos sociais se apropriam, vivenciam e conferem sentido a esses dispositivos tecnológicos, que são, como toda tecnologia, intrinsecamente sociais.

Christine Hine ${ }^{3}$, em seu pioneiro livro Virtual Ethnography, de 2000, já indicava que a internet também é um artefato cultural, parte de um sistema simbólico, apreensível em seus sentidos a partir do plano local, bem como do ponto de vista particular dos sujeitos que dela se aproximam e que nela encontram usos e sentidos múltiplos e concretos. É sobre esses usos que nos debruçamos, nós, antropólogos/as, sem presumirmos, de antemão, que um ou

\footnotetext{
${ }^{3}$ Professora titular do Departamento da University of Surrey, no Reino Unido. Entre 2044 e 2008, foi presidente da Associação Européia para o Estudo da Ciência e da Tecnologia. Suas publicações mais conhecidas são "Virtual Ethnography” (2000), "Virtual Methods" (2005) e "Ethnography for the Internet” (2015).
} 
outro seja superior ou mesmo que essas tecnologias possam ser compreendidas a partir de seus respectivos manuais de usuário.

Também não pressupomos que a internet e seus dispositivos representem uma novidade absoluta, nem subestimamos a importância dos debates e conceitos clássicos da Antropologia e das Ciências Sociais para a investigação, análise e interpretação dos fenômenos sociais emergentes nesse campo. Um exemplo bastante interessante é o quanto o conceito de "etnografia multisituada", proposto por George Marcus (1995), é apropriado de modos bastante inovadores pela antropologia digital como um todo e, especificamente, em vários artigos deste dossiê. Isso mostra o quando a ideia de etnografia multisituada é útil para pensar a internet e suas relações e conexões, na medida em que aponta para um certo holismo (discutido também por Hine) e para a ruptura com barreiras espaciais e contextuais muito delimitadas. Isso, por sua vez, não nos tem impedido de perceber e investigar fenômenos nativos dos ambientes online ou transformados de modo decisivo neles e por eles, como as dinâmicas sociais singulares observadas em determinados fóruns online, as regras de etiqueta formuladas para regularem condutas ou a intensificação de fenômenos sociais como a disseminação de fake news e discursos de ódio (ver FREITAS 2017) por meio dos novos dispositivos digitais. Temos tratado esses fenômenos de modo a rastrear suas conexões on e offline, pensando, sobretudo, em trânsitos, continuidades e em fluidez.

Vale ressaltar, nesse nosso breve balanço introdutório, que não estamos falando de um campo de estudos linear e livre de contenciosos. Se formos remontar aos seus primórdios, há um importante debate acerca das próprias nomenclaturas a serem utilizadas para delimitar esse espaço - e toda a discussão inicial se pautava pelas referências e metáforas espaciais, no que, Hine (2020), no texto traduzido neste dossiê, chama de "abordagem ciberespacial”. Naquele momento, falava-se em real e virtual, sendo que estes dois polos apareciam quase sempre de forma oposta, a partir de separações espaciais. Tal abordagem traz um problema de partida, na medida em que opor virtual ao real gera o risco de que o virtual, a internet e todas as relações que a permeiam e que ela proporciona, passem a ser vistos como menos reais e marcados como o local de relações menos importantes (ver PARREIRAS 2008; 2011), mais voláteis e uma parte separada da vida.

Em 2000, Miller e Slater, em texto traduzido para o português em 2004 e hoje espécie de cânone na antropologia digital brasileira, ao estudarem cibercafés em Trinidad, apresentam um argumento inovador e, nos parece, mais adequado ao entendimento contemporâneo dos modos como as pessoas fazem uso das tecnologias e especificamente da internet. Sua proposta é substituir o par de oposição real/virtual por online e offline, partindo da premissa de que não se trataria de mera modificação da terminologia ou da manutenção da dicotomia, mas sim, de repensar a própria relação entre o que está sendo chamado de online e de offline. Entre eles, haveria uma relação fluida, contextual e que só faz sentido a partir dos modos como os sujeitos dão sentido às suas práticas, aos seus usos e às relações que estabelecem. 
Outros dos contenciosos que vêm despertando debates importantes recentemente é a questão das desigualdades digitais, sobretudo quando pensamos nas possibilidades materiais de acesso - os dispositivos e as redes de conexão - e no domínio do uso destes dispositivos, dos sites, das plataformas, dos aplicativos entrelaçadas a outros marcadores sociais da diferença, como classe, raça, geração e gênero. Muitos dos textos que compõem este especial vão abordar ou sinalizar para esta questão, apontando a necessidade, em um país estruturalmente desigual como o Brasil, de levarmos a cabo estudos mais robustos sobre o tema.

Com a consolidação da internet sem fio e a popularização dos smartphones (ver LINS 2019), deixamos de "entrar na internet" e passamos a nela viver imersos, ou, no mínimo, a termos nossa vida cotidiana atravessada pela digitalização, que atinge até mesmo aqueles que não dispõem de acesso doméstico. Hoje, documentos institucionais e pessoais são digitalizados, serviços dos mais diversos tipos - privados e públicos - são acessíveis online e requerem acesso à internet via login (com uso de senha pessoal); atividades profissionais nos mais diversos campos, bem como atividades educacionais, supõem que se estabeleça um mínimo de relação com tecnologias digitais e comunicação online.

Assim, a dimensão prescritiva da tecnologia se torna clara no fato de que, como indivíduos, já não temos a escolha de recusa do digital, em sentido amplo. Podemos escolher não termos cadastro numa rede social como o Facebook ou não usarmos telefone celular. Há ainda pessoas e grupos sociais inteiros para quem tal escolha inexiste, seja, por exemplo, por falta de recursos financeiros para aquisição, de possibilidades para o aprendizado dos usos ou pela incompatibilidade com seu modo de vida. No entanto, o que queremos assinalar é o quanto a internet e o digital se tornaram pervasivos, presentes no cotidiano, para além da escolha ou preferência individual de entrar no Twitter ou aderir à prática de jogar online.

Exatamente por isso, por essa ampliação e disseminação das tecnologias digitais relacionadas à internet, o termo cibercultura e, antes dele, ciberespaço, foi sendo gradualmente abandonado e foi dando lugar ao digital. Falamos hoje mais frequentemente embora não exclusivamente - em antropologia do digital e antropologia digital, esta segunda, mais abrangente, incluindo pesquisas que fazem uso de ferramentas digitais ou estudam tecnologias digitais, não apenas a internet, mas também o vídeo, a fotografia, os celulares, os games, a ciência de dados, dentre outras possibilidades.

$\mathrm{Na}$ Antropologia, a reflexão metodológica costuma estar intrinsecamente vinculada à investigação do sujeito concreto de nossa pesquisa, o que implica em sermos, constantemente, pouco normativos em relação às escolhas metodológicas a serem adotadas. Implica também em trabalharmos de modo artesanal, passo a passo, adequando, e muitas vezes criando, nossas ferramentas de pesquisa na medida em que vamos avançando na investigação junto com nossos/as interlocutores/as em campo. 
Como tantos pesquisadores/as já disseram ${ }^{4}$, nós, como investigadores/as do social, nos interessamos por aquilo que interessa aos nossos/as interlocutores/as em campo. Só esta última condição, em boa parte dos casos, já seria suficiente para explicar o crescente interesse por pesquisar a internet e demais tecnologias digitais.

No entanto, como afirmamos anteriormente, vivemos hoje situações de mudança e adequações colocadas pela pandemia e o digital é peça fundamental neste processo. Neste caso específico, juntamente com as diferentes medidas de restrição de circulação de pessoas, muitas pesquisas passaram a ser realizadas por meios digitais e alguns pesquisadores foram obrigados a enfrentar novas questões, pertinentes a esse campo, e à busca de entendimento das próprias tecnologias e ambientes online, para além de sua mera instrumentalização como ferramenta de pesquisa. Mesmo como ferramenta, foi preciso pensar sobre elas, construir delas uma compreensão quanto ao seu papel numa metodologia de pesquisa. E isso se incorporou ao esforço contínuo que nós, pesquisadores/as do digital, já vínhamos realizando nessa área, em diálogo com outras áreas de pesquisa, como consumo, gênero, trabalho, dentre tantas outras.

Com a disseminação da digitalização e da midiatização das relações sociais cotidianas, em várias frentes, formais e informais, institucionais e interpessoais, muitas das questões que antes mobilizavam os especialistas em mídias e internet, passaram a despertar o interesse de especialistas desses outros campos. Isso só se acentuou com a transferência de parte das pesquisas para os ambientes online durante a pandemia. Na verdade, a pandemia só fez acentuar um movimento de expansão e diversificação dos estudos do digital que já vinha sendo observado há algum tempo.

Como aponta Hine (2015), ao realizar um balanço sobre os mais de 20 anos de pesquisas sobre o tema, notamos o quanto a etnografia tem sido um meio bastante estratégico para conduzir pesquisas e para sair de uma visão que toma a internet como uma mônada fechada em si mesma. Os textos deste dossiê corroboram esta ideia, mostrando diversas particularidades, usos e nuances de "etnografias para a internet". Nesse cenário, a internet aparece como campo de estudo, como ferramenta de pesquisa ou como contexto, sendo que cada vez mais fica claro o quanto sua importância não pode ser negligenciada na vida dos sujeitos.

No que se refere à composição deste dossiê, temos a já mencionada tradução de Christine Hine, realizada por Carolina Parreiras e Beatriz Accioly Lins. Hine é uma das mais importantes antropólogas do campo de estudos digitais. Desde o já citado Virtual Ethnography (2000), a autora traz provocações bastante fundamentais para pensarmos os usos e o caráter multifacetado das tecnologias e da internet. Ainda que tenha sido entendido como um manual, esta obra está longe de ser um guia de respostas para os nascentes estudos antropológicos sobre o "virtual". Ao contrário, a obra é um compêndio de perguntas e questões que atestam a importância e a rentabilidade da perspectiva etnográfica para

\footnotetext{
${ }^{4}$ Como afirmou Daniel Miller (2017), na apresentação "Digital Anthropology", "we follow what happens in the world, if the world goes digital, we go digital“. Ver aqui.
} 
compreender a internet e os usos que as pessoas faziam dela. Assim, ainda que se situe em um momento inicial dos estudos, este é um livro que continua a ser fundamental.

Em 2015, Hine publica Ethnography for the Internet, sendo que o texto traduzido é o capítulo dois deste livro. Já no título notamos a mudança de nomenclaturas: some o virtual e em seu lugar aparece a internet, precedida da preposição "para" que, sobretudo, quer marcar uma nova perspectiva entre posições que advogam uma etnografia da internet (como se ela fosse simplesmente um todo apreensível) e etnografia na internet (que traz o risco de manter a visão de que se trata apenas de um espaço). O "para" aponta exatamente algo que frisamos acima: a internet é campo, é contexto e é ferramenta de pesquisa, composta pelas muitas relações que se desenvolvem nela e a partir dela. Assim, Hine (2020) afirma que a internet contemporânea é marcada por três características: incorporada (embedded), corporificada (embodied) e cotidiana (everyday). Estes três eixos seriam, portanto, pontos de partida para etnografias para a internet.

Como dito anteriormente, a composição deste dossiê Estratégias para pensar a digital prima pela diversidade temática e de formas de abordagem de temas relativos ao digital. Um primeiro eixo de artigos se dedica a reflexões sobre os aspectos metodológicos e éticos relativos à realização de pesquisas que tomam como foco a internet e o digital. Em outro eixo, aparece a preocupação com os muitos usos das tecnologias, havendo uma atenção especial aos modos como os sujeitos delas se apropriam cotidianamente e com as implicações políticas destes usos. Em alguns deles, vemos o desafio de pensar sobre os impactos da pandemia da Covid-19 nas pesquisas realizadas e na vida dos sujeitos que nelas aparecem.

Renato Lemos (2020), em seu artigo sobre guerrilhas digitais, reflete sobre os processos de poder em torno da formatação dos dados digitais e das próprias Tecnologias de Informação e Comunicação (ICTs), abordando questões como os mecanismos de exclusão. Além disso, ao pensar sobre as infraestruturas do digital, traz importantes reflexões sobre as formas de resistência e de produção de contranarrativas por meio das "guerrilhas digitais" e dos "hackeamentos".

No artigo de Júlia Batista e Érica Renata de Souza (2020), é apresentada uma revisão de pesquisas em gênero e sexualidade em sua intersecção com a Antropologia da Ciência e Tecnologia. A partir de levantamento de trabalhos nos anais da ReacT e da RBA, as autoras refletem acerca das possibilidades apresentadas pelo aparato tecnológico e pelos sistemas de conexão para o fazer etnográfico, bem como estão sendo moldados novos corpos, novos sujeitos e novos saberes.

Sheila dos Santos traz uma interessante reflexão sobre a realização de pesquisa no aplicativo Tinder, que permite "a busca afetivo-sexual online". A partir da narrativa sobre o fluxo de sua pesquisa, a autora mostra as implicações metodológicas e éticas envolvidas tanto em estar online quanto no que se refere a interagir em um aplicativo de encontros, na medida em que ela mesma se encontrava sujeita aos "matches" (que são o que tornam a pesquisa possível, mas se situam em uma linha tênue no caso de uma pesquisadora lidando com sexualidade e desejos). 
Felipe Piva, por sua vez, tem como propósito entender como os atuais processos de disputa política em torno da significação de categorias de violências sexuais ocorridas em contexto universitários (como trotes e festas) têm sido apropriados e representados pela mídia hegemônica brasileira nos últimos anos. Em seu artigo, ele não apenas apresenta e analisa os resultados obtidos, mas também aponta estratégias possíveis para utilização do digital no campo de pesquisa antropológica e para a construção de um arquivo digital como base de dados.

O artigo de Patrícia Pinheiro et al (2020) discute as possibilidades de utilização do podcast na experiência de divulgação e comunicação científica em Antropologia, avaliando, em especial, dois aspectos: a circularidade entre mídias que constituem parte de uma rede sociotécnica, e a presença do digital como mobilizador de afetos nas e a partir das mídias.

Maria Pilar Cabanzo e Danielly Rodrigues (2020) apresentam um instigante artigo sobre o uso do digital para o ensino de espanhol na favela da Maré (Rio de Janeiro). O foco principal é o uso do Whatsapp e, a partir dele, as autoras/professoras discutem as formas de interação das/os participantes e os aspectos relativos ao aprendizado da língua espanhola. Sobretudo, destaca-se o que é chamado de "fluidez das práticas linguísticas" no trânsito contínuo entre online e offline e que pode ser percebido na análise feita do dicionário português/espanhol, montado a partir de palavras do cotidiano das/os alunas/os e construído coletivamente.

Jorge Cárdenas (2020) traz um artigo bastante atual, situado no contexto mexicano, no qual aborda alguns dos impactos da pandemia de Covid-19 entre jovens universitários. Além disso, discute os aspectos metodológicos da realização da pesquisa, partindo do conceito de "etnografia multisituada", de George Marcus. A partir das "conexões e desconexões" das/os alunas/os, o autor propõe pensar nos desafios colocados pelo uso das tecnologias - que têm acesso altamente desigual - na educação.

O artigo de Isabela Furtado (2020) analisa uma tecnologia de monitoramento de sinais vitais, recentemente adotada em um aplicativo de mapeamento de infecções de Covid19, utilizado no Sistema Único de Saúde (SUS). A partir disto, a autora reflete sobre as tecnologias de reconhecimento facial, pontuando questões como vigilância de dados, controle algorítmico e se perguntando sobre a relevância de tal tipo de tecnologia para registro de infectadas/os durante a pandemia.

Ítalo Gonçalves (2020) traz à baila uma discussão acerca das noções de "plataforma" e "plataformização" (da web e do social), sinalizando algumas maneiras pelas quais tal reflexão pode propor revisão de práticas etnográficas, especialmente aquelas realizadas em contextos online. Para tanto, ele apresenta um panorama dos estudos de plataforma, repensando "campo etnográfico", tal qual a ideia de "etnografia multissituada", trazida por Marcus (1995) e sugerindo outras dinâmicas, bem como outros contornos e significados.

O artigo de Helena Mônaco (2020) propõe reflexões éticas e metodológicas a respeito de pesquisas em ambientes digitais a partir dos desdobramentos de tentativas de consentimento para a realização da investigação. Para a autora, os usos e sentidos da noção 
de consentimento variam de acordo com sujeitos e ambientes digitais que eles ocupam. $\mathrm{O}$ texto aborda duas situações etnográficas, vivenciadas em temporalidades distintas e junto a grupos diferentes numa mesma plataforma digital, o Facebook.

Luiz Augusto Mugnai Vieira Júnior (2020), a partir da experiência de um estudo antropológico sobre a recepção da transexualidade nas mídias digitais, descreve procedimentos de imersão em plataformas online, refletindo, também, a respeito da prática e do comportamento do/a antropólogo/a enquanto um/a observador/a oculto/a digital.

Por fim, Agostina Dolcemascolo e Lucila Dughera (2020) resgatam e analisam três experiências de pesquisa com o objetivo de pensar os obstáculos, problemas e desafios que cientistas sociais enfrentam ao lidar com fenômenos relacionados às tecnologias digitais e à internet em três aspectos: como delimitar o objeto, como acessar os dados e como coletar as informações. No mais, as autoras também trazem um aspecto transversal remete à questão ética em pesquisas do e no digital: como estabelecer limites.

Nosso objetivo ao propor este dossiê - Estratégias para pensar o digital - foi, então, agregar um conjunto de reflexões sobre teoria, métodos e ética em pesquisas que levem em consideração a internet e os variados usos do aparato tecnológico digital. O resultado, como fica claro pelos textos selecionados, foi a junção de estudos realizados em diferentes contextos, com focos variados e que utilizam uma mistura de técnicas de pesquisa (ainda que a etnografia seja dominante). Em sua totalidade, estes artigos - e vale ressaltar que eles dizem respeito não só ao Brasil, mas a outros países da América Latina - atestam o vigor deste campo de estudos e demonstram o quanto ainda há para ser debatido frente à maleabilidade da tecnologia, aos rápidos e incessantes desenvolvimentos tecnológicos e, sobretudo, aos usos múltiplos, inventivos e até mesmo desafiadores que as pessoas fazem destas tecnologias e das redes de conexão.

\section{Referências Bibliográficas}

BATISTA, Júlia Vargas; SOUZA, Érica Renata de. (2020). Gênero, ciência e etnografia digital: Aproximações e potencialidades. Cadernos de Campo, vol.29, n.2 pp.e175199

Cabanzo, Maria Pilar; RODRIGUES, Daniela. (2020). Apuntes etnográficos sobre lo digital y la lengua en Maré, Rio de Janeiro. Cadernos De Campo, vol.29, n.2, pp.e175263.

CÁRDENAS, Jorge Alberto Meneses. (2020). Etnografía digital multisituada: jóvenes universitarios y universitarias estudiando desde casa en tiempos decovid-19. Cadernos De Campo, vol.29, n. 2, pp.e175177

FREITAS, Eliane Tânia; RAMOS, Jair de Souza. (2017). Etnografia digital. Revista Antropolítica, n. 42, p.8-15.

FREITAS, Eliane Tânia. (2017). Linchamentos virtuais: Ensaio sobre o desentendimento humano na internet. Revista Antropolítica, Niterói, n. 42, p.140-163. 
FURTADO, Isabela Crispim Brito. (2020). Capturando sinais vitais pelo seu smartphone: uma tecnologia de reconhecimento facial para saúde. Cadernos De Campo, vol.9, n.2, pp.e175204

GEERTZ, Clifford. (2012). A Interpretação das Culturas. Rio de Janeiro, Editora LCT.

GONÇALVES, Ítalo Vinicius. (2020). Da etnografia multissituada à "plataformizada": aproximações entre antropologia e estudos de plataforma. Cadernos de Campo, vol.29, n.2, pp.e175274

DOLCEMASCOLO, Agostina; DUGHERA, Lucila. (2020). Limitaciones y desafíos del quehacer de las y los cientistas sociales en el capitalismo informacional. Un abordaje desde el análisis de tres experiencias de investigación. Cadernos De Campo, vol.29, n.2, pp.e175285.

HINE, Christine. (2000). Virtual Ethnography. London: Sage.

HINE, Christine. (2015). Ethnography for the Internet. Embedded, embodied and everyday. London/New York: Bloomsbury, 2015.

HINE, Christine. (2020). A internet 3E: uma internet incorporada, corporificada e cotidiana. Cadernos De Campo, vol.29, n.2, p. e181370

LEMOS, Renato de Lyra. (2020). Guerrilha digital e produção de contranarrativas: resistindo aos impactos dos mecanismos de dominação de memória na internet. Cadernos De Campo, vol.29, n.2, pp. e175020.

LINS, Beatriz Accioly. (2019). Caiu na rede: mulheres, tecnologias e direitos entre nudes e (possíveis) vazamentos. Tese de Doutorado em Antropologia. São Paulo: Faculdade de Filosofia e Ciências Humanas/Universidade de São Paulo.

LINS, Beatriz Accioly. (2020). “A internet é o celular”: uma antropóloga entre smartphones, câmeras frontais e redes sociais. Internet \& Sociedade, n.2, vol. 1.

MARCUS, George. (1995). Ethnography in/of the World System: The Emergence of MultiSited Ethnography. Annual Review of Anthropology, vol. 25, p. 95 - 177.

MILLER, Daniel. (2017). “Digital Anthropology”. Serious Science, 24 de Agosto de 2017. http://serious-science.org/digital-anthropology-8688

MILLER, Daniel; SLATER, Don. (2004). Etnografia on e off-line: cibercafés em Trinidad. Horizontes Antropológicos, vol. 10, n. 21, 2004.

MILLER, Daniel; HORST, Heather. (Eds). (2012). Digital Anthropology. London/New York: Berg, 2012.

MONACO, Helena Motta. (2020). Quem cala consente? Ambientes digitais e suas implicações para a pesquisa antropológica. Cadernos De Campo, vol29, n.2, pp.e175295

PARREIRAS, Carolina. (2011). "Não leve o virtual tão a sério”? - uma breve reflexão sobre métodos e convenções na realização de uma etnografia do e no online. In: FERIANI, Daniela Moreno; CUNHA, Flávia Melo da; DULLEY, Iracema. (orgs). Etnografia, Etnografias. Ensaios sobre a diversidade do fazer antropológico. São Paulo: Annablume.

PARREIRAS, Carolina. (2012). Altporn, corpos, categorias e cliques: notas etnográficas sobre pornografia online. Cadernos Pagu, n. 38, p. 197- 222. 
PARREIRAS, Carolina. (2017). Pornografias.com: as convenções do altporn. Revista Antropolítica. Niterói, n. 42.

PARREIRAS, Carolina; MACEDO, Renata M. (2020). Desigualdades digitais e educação: breves inquietações pandêmicas. In: GROSSI, Miriam; TONIOL, Rodrigo. (Orgs). Cientistas Sociais e o Coronavirus. São Paulo: ANPOCS, 2020.

PINHEIRO, Patrícia dos Santos; FREITAS, Camilla Iumatti; MAUX, Anatil; SACCO, Stephanie; MACHADO, Glauco Fernandes. (2020). Desconfinando ideias: reflexões sobre mídias digitais e a circulação do conhecimento antropológico a partir do podcast. Cadernos De Campo, vol., n.2, pp.e175301.

PIVA, Felipe Paes. (2020). Estratégias antropológicas incipientes para uma etnografia digital: uma discussão a partir de narrativas midiáticas sobre violências sexuais, de gênero, e trotes numa Faculdade de Medicina. Cadernos De Campo, vol.29, n.2, pp.e175324.

SANTOS, Sheila Cavalcante dos. (2020). Imersões, fluxos e desafios em uma etnografia no Tinder. Cadernos De Campo, vol.29, n.2, pp.e175168

VIEIRA JUNIOR, Luiz Augusto Mugnai. (2020). A imersão oculta em plataformas online: uma experiência antropológica a partir dos estudos de recepção. Cadernos De Campo vol.29, n.2, pp.e175275

sobre as autoras

\section{Beatriz Accioly Lins}

Doutora em Antropologia Social (USP) e pesquisadora do NUMAS/USP - Núcleo de Estudos sobre Marcadores Sociais da Diferença.

\section{Carolina Parreiras}

Pesquisadora de pós-doutorado do Departamento de Antropologia da Universidade de São Paulo e membro do NUMAS/USP - Núcleo de Estudos sobre Marcadores Sociais da Diferença.

\section{Eliane Tânia Freitas}

Professora associada de antropologia no Departamento de Antropologia da UFRN. 
LINS; PARREIRAS; FREITAS | Estratégias para pensar o digital | 11 